\title{
Knowledge, Attitude, and Practice (KAP) Regarding HIV/AIDS Transmission and Prevention Among Inmates in Bushehr Prison, 2009-2010
}

\author{
Razieh Bagherzadeh ${ }^{1, *}$; Nasrin Zahmatkesan ${ }^{2}$; Hamideh Rashidi ${ }^{3}$; Roghayeh Gashmard $^{4}$; \\ Kamran Mirzaei ${ }^{5}$ \\ ${ }^{1}$ Department of Midwifery, Bushehr University of Medical Sciences, Bushehr, IR Iran \\ ${ }^{2}$ Department of Paramedical, Yasuje University of Medical Sciences, Yasuje, IR Iran \\ ${ }_{4}^{3}$ Bushehr Prison, Bushehr, IR Iran \\ ${ }^{4}$ Department of Nursing Bushehr University of Medical Sciences, Bushehr, IR Iran \\ 5 Department of Community Medicine, Bushehr University of Medical Sciences, Bushehr, IR Iran \\ ${ }^{*}$ Corresponding author: Razieh Bagherzadeh, Department of Midwifery, Bushehr University of Medical Sciences, Bushehr, IR Iran. Tel: +98-7733450187, Fax: +98-7714550187, \\ E-mail: r.bagherzadeh@bpums.ac.ir
}

Received: June 5, 2015; Revised: August 2, 2015; Accepted: August 8, 2015

\begin{abstract}
Background: HIV has been recognized as an important problem in prisons because of the common practice of needle sharing and unsafe sex. Assessment of knowledge, attitude, and practice (KAP) apropos HIV/AIDS in prisons is needed to devise educational programs.

Objectives: This research was performed to assess KAP regarding HIV|AIDS transmission and prevention among Bushehr Prison inmates. Patients and Methods: This analytical cross-sectional study was conducted between 2009 and 2010 among 800 inmates in Bushehr Prison. Convenience sampling was utilized, and the inclusion criteria comprised Iranian nationality, ability to speak or read and write in Farsi, and a prison stay for at least 2 months before entering the study. The data collection tool was a self-designed questionnaire, consisting of close-ended questions in 4 sections: demographic information, 36 questions on knowledge (total score ranging from 0 to 36), 20 questions on attitude (total score ranging from 0 to 40), and 7 questions on practice. Content validity was confirmed by using subject matter experts. Reliability was confirmed via a pilot study and Cronbach's $\alpha$ method. The $\alpha$ coefficients were between 0.75 and 0.95 for the different sections. The data were analyzed using descriptive and inferential statistics.

Results: The mean score of HIV/AIDS knowledge in the male and female inmates was $23.84 \pm 4.70$ and $21.35 \pm 6.28$, respectively $(\mathrm{P}<0.001)$. The mean score of HIV/AIDS attitude among the men and women was $26.6 \pm 5.4$ and $24.48 \pm 7.6$, correspondingly $(\mathrm{P}<0.001)$. Additionally, $63.3 \%$ of the male and $57.3 \%$ of the female inmates had read about HIV|AIDS $(\mathrm{P}=0.20), 4 \%$ of the men and $11.3 \%$ of the women had tattooing in prison, and $28.5 \%$ of the men and $32.5 \%$ of the women had participated in HIV|AIDS prevention classes $(\mathrm{P}=0.29)$.

Conclusions: Comprehensive programs on HIV/AIDS education and counseling are needed to improve KAP apropos HIV risk factors and reduce risk behavior among prison inmates, especially women.
\end{abstract}

Keywords: Knowledge; Attitude; Prevention; HIV; Prisons

\section{Background}

Human immunodeficiency virus infection and acquired immune deficiency syndrome (HIV/AIDS) has become the most important public health problem since the Second World War. The latest epidemiological studies in 2013 reported 35 million cases of HIV/AIDS. The prevalence of people living with HIV in Iran was estimated to be between 47,000 and 110,000 in 2013 (1). Any individual may be at risk for HIV, but some groups of individuals are at a higher risk for exposure to HIV. Imprisonment is a risk factor for HIV infection because of the common practice of needle sharing and unsafe sex (2-4). Many knowledge, attitude, and practice (KAP) studies have been conducted on HIV/AIDS in prisons. The level of KAP apropos HIV/AIDS is different in different communities. One study showed that very few individuals staying in working women's hostel or Dormitory had adequate knowledge about the modes of transmission and methods of prevention (5).
In a study at Rajaeeshahr Prison, in Iran, the rate of correct answers on the transmission modes of HIV was between $69 \%$ and $99 \%$. In this prison, the prevalence of needle sharing was $23 \%$ (6). In a prison in the Iranian city of Kerman, the level of knowledge of the inmates about HIV/ AIDS was high, while information on prevention was inadequate (7). In a study at Ghezalhesar Prison, in the Iranian capital, Tehran, the prevalence rates of injection drug use, sexual intercourse, razor sharing, and tattooing were $22 \%$, $8 \%, 38 \%$, and $6 \%$, respectively (8). Knowledge about HIV|AIDS was found to be high in Quathing prisoners of Lesotho, but the inmates had misconceptions about HIV/AIDS and condom use (3). Since HIV/AIDS is an incurable disease and its control is extremely expensive, prevention programs are needed to control the rapid spread of this disease. Increasing awareness regarding HIV/AIDS can be a powerful means of fostering positive attitudes and building safe

Copyright (C) 2015, Ahvaz Jundishapur University of Medical Sciences. This is an open-access article distributed under the terms of the Creative Commons Attribution-NonCommercial 4.0 International License (http://creativecommons.org/licenses/by-nc/4.0/) which permits copy and redistribute the material just in noncommercial usages, provided the original work is properly cited. 
practices among populations. Hence, a clear and comprehensive KAP plan vis-a-vis HIV/AIDS among any population is of vital importance for measures aimed at controlling or preventing the spread of the disease (9). Before formulating public health policies for the prevention of HIV, it is critical to obtain information on KAP regarding HIV.

In recent decades, HIV infection has dramatically increased among Iranian prisoners. Some authors have suggested that this could be due to lower levels of information about HIV and its transmission ways (10).

Most KAP studies on HIV in prisons have been done on men. In studies that have examined gender differences in the level of KAP regarding HIV in prisons, the percentages of women in the samples were low (11-14). The present study examined gender differences in KAP concerning HIV/AIDS in equal numbers of male and female inmates.

Bushehr is an Iranian port city, and the general population in this city is at high risk for HIV/AIDS. Needless to say, prison inmates in this city are higher risk for HIV/AIDS than the general population. Nonetheless, no studies have been hitherto conducted on KAP toward HIV transmission and prevention among prisoners in this city. Devising educational and counselling programs for prisoners in Bushehr Prison requires an assessment of their KAP regarding HIV/AIDS. The results of this study and similar studies in other prisons in the country can be a step toward a full understanding of prisoners' KAP concerning HIV prevention.

\section{Objectives}

This research was performed to assess KAP regarding HIV/AIDS among male and female inmates in Bushehr Prison.

\section{Patients and Methods}

The study was designed as an analytical cross-sectional study and was conducted between 2009 and 2010 among a sample of male and female Bushehr Prison inmates. The sample size was determined via a pilot study on 30 male and 30 female prisoners. In the pilot study, $58 \%$ of the male and $51 \%$ of the female inmates had good knowledge of HIV/AIDS. The sample size was determined using the following equation:

$$
n=\frac{\left(z_{1-\frac{\alpha}{2}}+z_{1-\beta}\right)^{2} \times\left[p_{1}\left(1-p_{1}\right)+p_{2}\left(1-p_{2}\right)\right]}{\left(p_{1}-p_{2}\right)^{2}}
$$

Type I error $(\alpha)$ of 0.05 and a type II error $(\beta)$ of 0.2 were assumed. Four hundred samples for each group were determined. Eight hundred (400 male and 400 female) inmates gave informed consent and were enrolled in the study. Due to the low number of women in the prison at a certain time, it took a year to collect data from the prisoners. Accordingly, convenience sampling was performed for male and female inmates. The inclusion criteria were comprised of Iranian nationality, ability to speak or read and write in Farsi, and a prison stay of at least 2 months before entering the study.

The study instrument was a self-administered questionnaire. A KAP questionnaire was developed based on the existing instruments used in previous research $(7,15,16)$. Also, the scaling and scoring of the questionnaire was based on the aforementioned literature. This questionnaire consisted of close-ended questions and contained 4 sections. Section I included demographic information. Section II focused mainly on knowledge and consisted of 36 questions about the transmission modes of HIV, methods of diagnosis, and high-risk groups; two such questions are as follows: "Which of the following body fluids can transmit HIV?" and "Which groups are not at risk for HIV/AIDS?". Section III encompassed 20 statements about attitude toward HIV/AIDs and HIV-positive people; two such statements are as follows: "I believe that people with HIV/AIDS should not' work in society." and "If I am infected with HIV, I will go far away." And finally, Section IV comprised 7 questions about practice. Each knowledge question had 2 responses: true and false. For each correct answer one point and for each false answer zero points were assigned. The total score of knowledge was between 0 and 36. Total scores ranging from 0 to 12,13 to 24 , and higher than 24 denoted good, moderate, and low levels of knowledge, respectively. The questions on attitude had 3 responses: a positive attitude toward each question was assigned 2 points; "I do not' know." was given 1 point; and a negative attitude was accorded zero points. The total score of attitude was between 0 and 40 . Total scores ranging from 0 to 13, 14 to 26, and higher than 26 denoted negative, neutral, and positive attitudes, correspondingly.

To establish face validity and to determine how long the questionnaire would take to complete, we piloted the questionnaire with 10 prison inmates. After the inmates individually completed the questionnaire, their 'overall understanding and interpretation of the questionnaire (ie, words, terms, phrases, directions, etc.) were examined. The average time of questionnaire completion time was $14 \pm 3$ minutes.

Content validity was confirmed by using subject matter experts. Grammar, wording, item allocation, scoring, and scaling were evaluated by 10 experts in the field of infectious diseases, health education, and community medicine. These experts were given the list of the content domains specified in the test blueprint, along with the test items intended to be based on each content domain. Then the experts were asked to indicate whether or not they agreed that each item was appropriately matched to the content domains. Three items that the experts identified as being inadequately matched to the test blueprint were revised by the researchers. Questionnaire reliability was confirmed by a pilot study using Cronbach's $\alpha$ method. The $\alpha$ coefficients for the knowledge, attitude, and practice questions were $0.95,0.80$, and 0.75 , respectively. The questionnaire was completed through face-to-face interviews for the illiterate or low-literate participants. Participants with adequate lit- 
Bagherzadeh Ret al.

eracy individually completed the questionnaire. The study was performed in compliance with the Deceleration of Helsinki and was approved by the institutional ethics committee of Bushehr University of Medical Sciences. Informed consent was obtained from each participant. The participants were assured of the confidentiality of information. To observe confidentiality, we did not mention the name of the participants in the questionnaire. The data were coded and entered into Statistical Package for the Social Sciences (SPSS), version 16, and analyzed using descriptive and inferential statistics such as independent-samples $t$-test, oneway analysis of variance, and $\chi^{2}$ test. For all the statistical tests, a P value less than 0.05 was considered significant.

\section{Results}

The mean age of the participants was $30.64 \pm 9.48$ years. The mean age of the men and women was $32.24 \pm 8.76$ (ranging from 16 to 74 years) and 29.04 \pm 9.91 (ranging from 16 to 65 years), respectively. The prevalence of good, moderate, and poor knowledge was $46.3 \%, 47.5 \%$, and $25 \%$ in the women and $60.3 \%, 39 \%$, and $0.8 \%$ in the men, correspondingly. The respective mean score of HIV knowledge in the men and women was $23.84 \pm 4.70$ and $21.35 \pm 6.28$. The mean difference in knowledge scores about HIV between the men and women was statistically significant $(P<0.001)$. The prevalence of positive, neutral, and negative attitude was $37.5 \%, 57 \%$, and $5.5 \%$ in the women and $51.3 \%, 47.8 \%$, and $1 \%$ in the men, respectively. The corresponding mean score of attitude regarding HIV in the men and women was $26.6 \pm$ 5.4 and $24.48 \pm 7.6$. The mean difference in attitude toward HIV between the men and women was statistically signifi- cant $(\mathrm{P}<0.001)$. Additionally, $78 \%$ of the men and $80.3 \%$ of the women knew that HIV/AIDS was an infectious disease (P $=0.051) ; 72.3 \%$ of the men and $67 \%$ of the women were aware that the appearance of an HIV carrier did not show this disease $(P=0.017) ; 70.3 \%$ of the men and $60 \%$ of the women knew that AIDS was a preventable disease $(\mathrm{P}<0.001) ; 66.8 \%$ of the men and $63.5 \%$ of the women knew that there was no effective treatment for HIV/AIDS ( $\mathrm{P}=0.037$ ); $65.3 \%$ of the men and $41.8 \%$ of the women believed that most of the people infected with HIV were not aware of their disease ( $P$ $<0.001$ ); and $79.5 \%$ of the men and $55.8 \%$ of the women believed that if individuals with HIV infection had no sign or symptom, they could transmit HIV $(\mathrm{P}<0.001)$. The demographic characteristics of the participants in the study are presented in Table 1 . The correct answers to the questions on knowledge and attitude concerning HIV in the men and women are tabulated in Table 2 Table 3, and a comparison of the knowledge and attitude scores based on the demographic data is shown in Table 4.

Our findings revealed that $63.3 \%$ of the men and $57.3 \%$ of the women had read about HIV/AIDS $(P=0.20)$, and $28.5 \%$ of the men and $32.5 \%$ of the women had participated in HIV/AIDS prevention classes $(\mathrm{P}=0.029)$. Injection drug use was reported by $11.8 \%$ of the men and $6 \%$ of the women $(\mathrm{P}=0.013)$. All the study participants had at least 1 instance of needle sharing. Tattooing was reported in $4 \%$ of the men and $11.3 \%$ of the women $(\mathrm{P}<0.001)$; none of the study population had a' prevention strategy for this procedure. Furthermore, $52.5 \%$ of the men and $43.3 \%$ of the women selected correct precautionary measures for a trip to the hairdresser's.

\begin{tabular}{|c|c|c|}
\hline Variable & Women & Men \\
\hline \multicolumn{3}{|l|}{ Education } \\
\hline Illiterate and primary school & $125(31.3)$ & $78(19.5)$ \\
\hline Pre high school & $129(32.3)$ & $174(43.5)$ \\
\hline High school & $97(24.3)$ & $115(28.8)$ \\
\hline Graduate & $29(7.3)$ & $32(8.0)$ \\
\hline Unanswered & $20(5)$ & $1(0.3)$ \\
\hline \multicolumn{3}{|l|}{ Marital status } \\
\hline Single & $106(26.5)$ & $211(52.8)$ \\
\hline Married & $234(58.5)$ & $186(46.5)$ \\
\hline Unanswered & $60(15.0)$ & $3(0.8)$ \\
\hline \multicolumn{3}{|c|}{ Residency before entering the prison } \\
\hline Urban & $234(58.5)$ & $289(72.3)$ \\
\hline Rural & $122(30.5)$ & $110(27.5$ \\
\hline Unanswered & $44(0.11)$ & $1(0.3)$ \\
\hline \multicolumn{3}{|l|}{ Employment status } \\
\hline Unemployment & $94(23.5)$ & $106(26.6)$ \\
\hline Worker & $8(2.0)$ & $104(26.0)$ \\
\hline Officer & $9(2.3)$ & $19(4.8)$ \\
\hline Self-employed & $205(51.3)$ & $168(42.0)$ \\
\hline Unanswered & $84(21.0)$ & $3(0.8)$ \\
\hline
\end{tabular}




\begin{tabular}{|c|c|c|c|}
\hline \multirow{2}{*}{ Questions } & \multicolumn{2}{|c|}{ Percentage of Correct Answers } & \multirow{2}{*}{ P Value } \\
\hline & Men & Women & \\
\hline \multicolumn{4}{|l|}{ Method of HIV/AIDS transmission } \\
\hline Touching an infected person & 85.6 & 68.5 & $<0.001$ \\
\hline Public toilets & 79.3 & 65 & $<0.001$ \\
\hline Tattooing & 85 & 81 & 0.024 \\
\hline Kissing & 75.8 & 48.8 & $<0.001$ \\
\hline Sexual intercourse & 89.5 & 82 & $<0.001$ \\
\hline Sting of insects & 45.8 & 33.3 & $<0.001$ \\
\hline Sharing cups and plates & 65 & 51.3 & $<0.001$ \\
\hline Sharing used needles & 88.8 & 79 & $<0.001$ \\
\hline Sharing bathrooms & 72.8 & 46.8 & $<0.001$ \\
\hline Sharing toothbrushes & 72.5 & 79 & 0.007 \\
\hline Shaving devices & 84.5 & 84.8 & 0.078 \\
\hline Sneezing and coughing & 70 & 60 & $<0.001$ \\
\hline Touching doorknobs & 82.5 & 62.8 & $<0.001$ \\
\hline \multicolumn{4}{|l|}{ Transmission via body fluids } \\
\hline Blood & 88.8 & 91.8 & 0.034 \\
\hline Teardrop & 77 & 61.3 & $<0.001$ \\
\hline Semen & 85.5 & 86 & 0.079 \\
\hline Saliva & 32.8 & 43.8 & $<0.001$ \\
\hline Urine & 59.5 & 43 & $<0.001$ \\
\hline Breast milk & 68.8 & 74.5 & 0.012 \\
\hline \multicolumn{4}{|l|}{ Which groups are not at risk for HIV/AIDS? } \\
\hline Blood donors & 40 & 37.8 & 0.047 \\
\hline Those engaging in unsafe sexual relationships & 59 & 70.5 & $<0.001$ \\
\hline Intravenous drug users & 51.8 & 59.8 & 0.004 \\
\hline Caregivers in unhygienic centers & 55 & 64.5 & $<0.001$ \\
\hline $\begin{array}{l}\text { If individuals with HIV infection have no sign or symptom, } \\
\text { they cannot transmit HIV. }\end{array}$ & 79.5 & 55.8 & $<0.001$ \\
\hline \multicolumn{4}{|l|}{ Useful ways for the prevention of HIV transmission } \\
\hline Refraining from blood donation & 79.3 & 70.5 & $<0.001$ \\
\hline Using condoms in sexual relationships & 73 & 54.8 & $<0.001$ \\
\hline Not using public toilets or pools & 24.3 & 21.8 & 0.047 \\
\hline Discontinuing relationships & 74 & 59 & $<0.001$ \\
\hline Onset of the sign or symptom of HIV/AIDS after exposure & 13.8 & 13.3 & $<0.001$ \\
\hline Time of testing after exposure & 10.3 & 6.8 & 0.021 \\
\hline In Iran, which group is the most susceptible to HIV infection? & 63.5 & 65.8 & 0.047 \\
\hline
\end{tabular}


Table 3. Percentage of the Positive Attitude Questions Regarding HIV/AIDS

\begin{tabular}{|c|c|c|c|}
\hline \multirow{2}{*}{ Questions } & \multicolumn{2}{|c|}{ Percentage of Positive Attitude } & \multirow{2}{*}{ P Value } \\
\hline & Men & Women & \\
\hline AIDS is a public health problem. & 61.3 & 37.8 & $<0.001$ \\
\hline I think using a condom can reduce the chance of HIV transmission. & 29.5 & 21.5 & 0.017 \\
\hline $\begin{array}{l}\text { I believe that for AIDS prevention, sterile syringes are needed for injec- } \\
\text { tion drug users. }\end{array}$ & 66.8 & 61 & 0.034 \\
\hline $\begin{array}{l}\text { I believe that only homosexuals and intravenous drug users are at risk } \\
\text { for HIV/AIDS. }\end{array}$ & 45.5 & 37.3 & 0.025 \\
\hline $\begin{array}{l}\text { I believe that only IV drug users are responsible for HIV transmission in } \\
\text { Iran. }\end{array}$ & 50.5 & 56.5 & $<0.001$ \\
\hline I permitted a person with HIV|AIDS to kiss my baby. & 27 & 23.3 & 0.005 \\
\hline $\begin{array}{l}\text { People with HIV/AIDS should inform their family and friends about } \\
\text { their disease. }\end{array}$ & 78.5 & 62 & $<0.001$ \\
\hline I may be infected with HIV. & 83.5 & 63 & $<0.001$ \\
\hline I believe that prisoners with HIV/AIDS should be isolated from others. & 25.5 & 18 & 0.034 \\
\hline $\begin{array}{l}\text { I believe that avoiding people with HIV/AIDS is needed for HIV/AIDS } \\
\text { prevention. }\end{array}$ & 38.8 & 36 & 0.026 \\
\hline $\begin{array}{l}\text { I believe that people with HIV/AIDS should not be allowed to work' in } \\
\text { society. }\end{array}$ & 32.3 & 29 & 0.018 \\
\hline I am worried that my family members are infected with HIV. & 54 & 37.8 & $<0.001$ \\
\hline $\begin{array}{l}\text { If my family members are infected with HIV, I will give them hope and } \\
\text { communicate with them. }\end{array}$ & 78.8 & 66.5 & $<0.001$ \\
\hline If I am infected with HIV, I will keep it a secret because of shame. & 57.8 & 42.5 & $<0.001$ \\
\hline If I am infected with HIV, I will go far away. & 56.3 & 36.3 & $<0.001$ \\
\hline If I am infected with HIV, I will inform my family and friends. & 69.3 & 57.5 & 0.007 \\
\hline I believe that HIV infection is an individual's destiny. & 60.3 & 51 & 0.002 \\
\hline I believe that only immoral individuals are infected with HIV. & 60.5 & 48.3 & $<0.001$ \\
\hline I believe that all prison inmates should be tested for HIV. & 83.8 & 73.5 & $<0.001$ \\
\hline I would like to be tested for HIV infection. & 85.3 & 76.8 & $<0.001$ \\
\hline
\end{tabular}

Table 4. Assessment of the Relationship Between the Demographic Characteristics of the Subjects and the Scores of Knowledge and Attitude

\begin{tabular}{|c|c|c|c|c|}
\hline \multirow[t]{2}{*}{ Variable } & \multicolumn{2}{|c|}{ Knowledge Score } & \multicolumn{2}{|c|}{ Attitude Score } \\
\hline & Mean \pm SD & PValue & Mean \pm SD & PValue \\
\hline Education & & $<0.001$ & & $<0.001$ \\
\hline $\begin{array}{l}\text { Illiterate or primary } \\
\text { school }\end{array}$ & $20.64 \pm 5.792$ & & $23.43 \pm 6.596$ & \\
\hline Pre high school & $22.15 \pm 5.503$ & & $25.24 \pm 5.981$ & \\
\hline High school & $24.26 \pm 5.234$ & & $26.50 \pm 6.902$ & \\
\hline Graduate & $26.66 \pm 3.683$ & & $31.93 \pm 5.385$ & \\
\hline Marital status & & 0.025 & & 0.006 \\
\hline Single & $23.38 \pm 5.291$ & & $26.49 \pm 6.351$ & \\
\hline Married & $22.48 \pm 5.451$ & & $25.16 \pm 6.592$ & \\
\hline Residence & & $<0.001$ & & $<0.001$ \\
\hline Urban & $23.27 \pm 5.317$ & & $26.36 \pm 6.216$ & \\
\hline Rural & $21.29 \pm 5.924$ & & $23.71 \pm 6.795$ & \\
\hline Employment status & & 0.082 & & 0.036 \\
\hline Unemployment & $21.67 \pm 5.665$ & & $24.65 \pm 6.494$ & \\
\hline Worker & $23.24 \pm 4.797$ & & $25.98 \pm 5.394$ & \\
\hline Officer & $22.68 \pm 5.491$ & & $26.29 \pm 6.841$ & \\
\hline Self-employed & $22.46 \pm 5.780$ & & $24.73 \pm 6.520$ & \\
\hline
\end{tabular}




\section{Discussion}

The results of the present study showed that about half of the participants had good knowledge about HIV/AIDS and that the level of knowledge among the men was higher than that among the women. The percentage of correct answers on some aspects of KAP regarding HIV/AIDS was very low, however. Two studies in the prisons of Iran showed high levels of knowledge among the inmates about HIV/ AIDS $(6,17)$. Hosseynnakhaee reported a lower level of knowledge in this regard in the male and female inmates in Kerman Prison (7). These results disagree with the findings of the present study. Such inconsistencies across the studies can be due to the difference in the quantity and quality of educational programs in different prisons for male and female inmates and also due to the sociocultural context where people have lived before entering prison. Educational programs should be planned according to the target population's cultural and socioeconomic status and must be comprehensive to cover all the aspects of the issue.

In the present study, positive attitude toward HIV/AIDS was lower among the women than among the man, which chimes in with the findings of a study by Meybodi and Mahmoudi Zarandi (16). The lower attitude score in the women may be due to their lower level of knowledge about HIV/AIDS. Many of the male and female inmates recruited in our study believed that people with HIV/AIDS should be isolated, which is discordant with the findings of a study by Hallajian (17). The level of knowledge of most of our study population was good insofar as they knew that HIV is not transmitted via sharing cups and plates, kissing, sneezing, and coughing; nonetheless, the majority also believed that HIV-positive individuals should be isolated, which calls for further awareness and counseling and cultural programs to foster a right attitude.

In the present study, the prevalence of intravenous drug use was lower than that reported in other studies $(6,8)$. Results pertaining this issue may not be reliable, however, because there is always the possibility of underreporting. In our culture, talking about substance abuse and homosexual relationships is fraught with difficulties because of the cultural aspects and stigmatization of such issues. Therefore, we opted not to include questions about sexual relationships. Those who inject drugs in prisons often share needles and syringes and other injecting equipment, which is a potent way of transmitting HIV (18). Inaccessibility of syringes and lack of knowledge about the dangers of shared needles have been reported as causes of needle sharing (19). Because syringe distribution programs are not implemented in Iranian prisons, interventions to raise knowledge about HIV transmission risk from sharing needles should be deemed an efficient way to reduce needle sharing.

Tattooing was more common in the women than in the men in our study. A review article demonstrated that one of the major risk factors for HIV infection among prison inmates was tattooing (10). Education of stan- dard precaution is, thus, of vital importance. There was a wide discrepancy between knowledge and behaviors vis-à-vis HIV/AIDS among the prison inmates recruited in the present study. Discrepancies between knowledge and behavior have been reported in other studies as well $(20,21)$. Strategic planning and continuous provision of educational programs and counseling that are culturally and socially tailored are needed in prisons.

Our results showed that the illiterate participants or those with a low level of education had lower scores in knowledge and attitude apropos HIV/AIDS. These results are not surprising and are consistent with those reported by some other studies $(15,22,23)$. The mean scores of knowledge and attitude of the inmates who lived in urban areas before incarceration were higher than those who lived in rural areas. The average attitude score of the prison officers was higher than that of the other occupational groups. Not only do individuals with more education and those residing in urban areas have better access to more information resources, but also they enjoy more social interaction, which can raise their level of knowledge and positive attitude. Single prison inmates had higher average scores of knowledge and attitude than their married counterparts in our study. This result is consistent with the finding of a study conducted by Askarian et al. (24) on nurses. This is probably due to the fact that single people have more time to learn and update their information.

The results of the current study can be used to design training programs and consulting services for HIV prevention and harm reduction in prisons with a view to improving the health of prisoners and moving toward healthy prisons. We recommend that further research on HIV risk behaviors and the impact of different educational programs and counseling be conducted to enhance KAP vis-à-vis HIV/AIDS among prisoners. This study had several limitations, first and foremost among which is the use of convenience sampling and self-report method for data collection.

\section{Acknowledgements}

Authors acknowledge all the participants involved in the project. We would like to thank Bushehr University of Medical Sciences for financial support.

\section{Authors' Contributions}

Study concept and design: Razieh Bagherzadeh and Roghayeh Gashmard. Data gathering and drafting of the manuscript: Hamideh Rashidi and Nasrin Zahmatkesan. Data analysis: Kamran Mirzaei. Revision of the manuscript: Razieh Bagherzadeh.

\section{Funding/Support}

This study was funded through a grant by Bushehr University of Medical Sciences. 


\section{References}

1. UNAIDS . Adult and children living with HIV 2013. AIDSinfo, Epidemiological status World Overview. 2013. Available from: http://www. unaids.org/en/dataanalysis/datatools/aidsinfo.

2. Salehi A, Naghshvarian M, Marzban M, Bagheri Lankarani K. Prevalence of HIV, HCV, and High-Risk Behaviors for Substance Users in Drop in Centers in Southern Iran. J Addict Med. 2015;9(3):181-7.

3. Akeke VA, Mokgatle M, Oguntibeju OO. Assessment of knowledge and attitudes about HIV/AIDS among inmates of Quthing Prison, Lesotho. West Indian Med J. 2007;56(1):48-54.

4. Chimphambano C, Komolafe I, Muula A. Prevalence of HIV, HepBsAg and Hep C antibodies among inmates in Chichiri prison, Blantyre, Malawi. Malawi Med J. 2007;19(3):107-10.

5. Sharma AK, Gupta A, Aggarwal OP. HIV/AIDS related knowledge, risk perception, attitude and sexual behavior of working women staying in hostels. Indian J Dermatol Venereol Leprol. 2001;67(1):21-4.

6. Eshrati B, Asl RT, Dell CA, Afshar P, Millson PM, Kamali M, et al. Preventing HIV transmission among Iranian prisoners: initial support for providing education on the benefits of harm reduction practices. Harm Reduct J. 2008;5:21.

7. Hosseynnakhaee F. Prisoners' knowledge of HIV/AIDS and its prevention in Kerman, Islamic Republic of Iran. East Mediterr Health J. 2002;8(6):725-31.

8. Karimi M, Niknami S, Heydarnia A. The effect of health education program on the AIDS preventive behaviors of prisoners aged under 25 years old (ghezalhesar prison-tehran). J Res in Med Sci. 2003;3(8):53-6.

9. Thanavanh B, Harun-Or-Rashid M, Kasuya H, Sakamoto J. Knowledge, attitudes and practices regarding HIV|AIDS among male high school students in Lao People's Democratic Republic. J Int AIDS Soc. 2013;16:17387.

10. Ghasemzadeh I, Shahri Zare R, Namazi SA, Sadeghi P, Shojaeddin S. Review of HIV risk factors in prison inmates in Iran. Life sci $j$. 2014;11(4s):236-9.

11. Adjei AA, Armah HB, Gbagbo F, Ampofo WK, Boamah I, AduGyamfi C, et al. Correlates of HIV, HBV, HCV and syphilis infections among prison inmates and officers in Ghana: A national multicenter study. BMC Infect Dis. 2008;8:33.

12. Kazerooni A, Joolaei H, Parsa N. Knowledge and attitude of male intravenous drug users on HIV/AIDS associated high risk behaviors in Shiraz Pir-Banon jail, Fars Province, Southern Iran. Iran Red Crescent Med J. 2010;2010(3):334-6.
13. Odujinrin MT, Adebajo SB. Social characteristics, HIV/AIDS knowledge, preventive practices and risk factors elicitation among prisoners in Lagos, Nigeria. West Afr $\mathrm{J}$ Med. 2001;20(3):191-8.

14. Zamani S, Farnia M, Torknejad A, Alaei BA, Gholizadeh M, Kasraee $\mathrm{F}$, et al. Patterns of drug use and HIV-related risk behaviors among incarcerated people in a prison in Iran. J Urban Health. 2010;87(4):603-16.

15. Mazloomi Mahmoodabad S, Mohammadpour M, Ehrampoosh M. A study on knowledge and attitude of soldiers of a military educational center in southeast of Iran about AIDS.J Military Med. 2005;7(2):101-7.

16. Meybodi Balali F, Mahmoudi Zarandi M. Knowledge and Attitude of Couples, Referring to Kerman Pre-marriage Counseling Center, towards AIDS, 2008. J Strid Dev Med Edu. 2012;6(2):173-80.

17. Hallajian H. Iranian epidemiological training programs for AIDS prevention in Mazandaran Province. Pak J Biol Sci. 2008;11(17):2109-15

18. Jurgens R, Ball A, Verster A. Interventions to reduce HIV transmission related to injecting drug use in prison. Lancet Infect Dis. 2009;9(1):57-66.

19. Mansorian M, Solhi M, Dehdari T, Taghdisi MH, Zamani Alvicheh F, Qorbani M, et al. The cause of utilization of shared needle among injecting drug users of Ahwaz city: a qualitative study. Razi J Med Sci. 2012;19(101):31-9.

20. Khajehkazemi R, Haghdoost A, Navadeh S, Setayesh H, Sajadi L, Osooli M, et al. Risk and vulnerability of key populations to HIV infection in Iran; knowledge, attitude and practises of female sex workers, prison inmates and people who inject drugs. Sex Health. 2014;11(6):568-74.

21. Sanou SM, Fokam JM, Mabvouna BR, Guetiya WR, Sali BB, Teikeu TV, et al. Knowledge, attitudes and practices on HIV/AIDS in the south region of Cameroon: case of the town of Kribi. Ig Sanita Pubbl. 2014;70(4):381-92.

22. Power KG, Marková I, McKee KJ, Kilfedder C. Correlates of HIV AIDS knowledge in a Scottish prison sample. Health Edu Res. 1996;11(3):287-97.

23. Siam S. Survey of Women's Knowledge about Aids in Rasht 2006. J Med Fac Guilan Univ Med Sci. 2008;65(17):59-67.

24. Askarian M, Hashemi Z, Jaafari P, Assadian O. Knowledge about HIV infection and attitude of nursing staff toward patients with AIDS in Iran. Infect Control Hosp Epidemiol. 2006;27(1):48-53. 